\title{
A study of effectiveness and safety of topical combination therapy for acne vulgaris patients in dermatology department of a tertiary care teaching hospital
}

\author{
Ravi R. Patel*, Bharti N. Karelia
}

Department of Pharmacology, PDU Government Medical College, Rajkot, Gujarat, India

Received: 19 December 2019

Revised: 05 February 2020

Accepted: 11 February 2020

*Correspondence:

Dr. Ravi R. Patel,

Email: ravipatel19922010@gmail.com

Copyright: (C) the author(s), publisher and licensee Medip Academy. This is an open-access article distributed under the terms of the Creative Commons Attribution Non-Commercial License, which permits unrestricted non-commercial use, distribution, and reproduction in any medium, provided the original work is properly cited.

\begin{abstract}
Background: Acne vulgaris is a dermatological disorder characterised by formation of comedones and inflammatory lesions. Acne is one of the most common reason for visiting a dermatologist in early adulthood. The current line of management for mild to moderate acne is topical medications with antimicrobials and retinoids. The present study assessed the effectiveness and safety of topical combination therapy for mild to moderate acne vulgaris.

Methods: An observational, prospective and comparative study conducted on newly diagnosed acne vulgaris patients who were treated with topical combination therapy. Changes in the total, inflammatory and non-inflammatory lesion counts, investigator global assessment (IGA) and dermatology life quality index (DLQI) scales were recorded to check effectiveness. Treatment emergent adverse events were recorded in suspected ADR reporting form for safety assessment.

Results: Participants $(\mathrm{n}=97)$ were treated with three topical combination treatments either clindamycin-benzoyl peroxide (group-A), clindamycin-adapalene (group-B) or benzoyl peroxide-adapalene (group C). Majority of participants $(42.3 \%)$ were treated with clindamycin-benzoyl peroxide group. Reduction from baseline of total, inflammatory and non-inflammatory lesion counts were highly significant within group comparison $(\mathrm{p}<0.001)$, but between group differences were not significant. Significant improvement in DLQI and IGA scores were noted in all three groups, but between group comparison showed no significant differences. All three groups were safe and well tolerated and equally improve participant's quality of life.

Conclusions: all three topical combination drugs for mild acne vulgaris had similar effectiveness in terms of reduction in acne lesions with similar safety profile.
\end{abstract}

Keywords: Acne vulgaris, Dermatology life quality index, Effectiveness, Safety

\section{INTRODUCTION}

Acne vulgaris is a common dermatological disorder of the pilosebaceous unit presenting usually at puberty. It is a chronic, self-limiting, inflammatory disease characterised by pleomorphic lesions like comedones, erythromatous papules, pustules, cysts and nodules. ${ }^{1}$ Although the course of acne may be self-limiting, the sequelae can be lifelong, with pitted or hypertrophic scar formation. ${ }^{2}$

Acne is one of the most common reason for visiting a dermatologist in early adulthood. ${ }^{3}$ Even though it is often perceived as a self-limited and not physically disabling disease of adolescence, its prevalence remains high into adulthood and its psychological impact can be striking, 
contributing to lower self-esteem, anxiety and depression. Consequently, there is significant patient driven demand for effective acne therapies, including prescribed medications and over the counter products. In addition, taking into account the need for long term treatment, there is increased need for topical medications that are popular with patients in order to achieve long term compliance. As a result, agents are available in a variety of formulations. These include topical antibiotics, retinoids and benzoyl peroxide in monotherapy or in combination products. Systemic medications also include antibiotics and retinoids as well as hormonal agents. ${ }^{4}$

Topical therapy is the standard of care for mild to moderate acne. Retinoids and antimicrobials such as benzoyl peroxide and antibiotics are the mainstay of topical acne therapy. Such treatments are active at application sites and they can prevent new lesions. The main objectives of this study were to assess the effectiveness of prescribed topical combination therapy for acne vulgaris and to evaluate safety and tolerability of prescribed topical combination therapy. Secondary objectives were to observe the demographic pattern of acne patients and to assess the impact of acne vulgaris therapy on quality of life parameters by dermatology life quality index (DLQI). ${ }^{5}$

\section{METHODS}

This was an observational, prospective and comparative study conducted on newly diagnosed acne vulgaris patients who were treated with topical combination therapy in Dermatology department of a tertiary care teaching hospital. The study was conducted from October 2016 to February 2018. Prior approval from head of the department of Dermatology was taken before the conduction of the study. The study was approved by Institutional Ethics Committee of Govt. Medical College (Date of approval - 27/09/2016, approval letter no.19014).

\section{Inclusion criteria}

Acne vulgaris patients of 15 to 35 years of age of either sex who were newly diagnosed by dermatologist and having $\geq 2$ to $\leq 30$ total lesions which could be inflammatory (papules and pustules) and/or noninflammatory (open or closed comedones) over face with investigator's global assessment score (IGA) 2 or $3 .^{6}$

\section{Exclusion criteria}

Patients with history of hypersensitivity to topical drug therapy, pregnant and lactating women and patients who was on topical corticosteroid mono-therapy were excluded.

Total 100 patients were included. All acne vulgaris patients attending acne clinic were reviewed. Informed consent was obtained from patients selected on the basis of inclusion and exclusion criteria before the enrolment into the study as participant. A suitable case record form was designed to collect all necessary and relevant information.

Included participants were followed up to four visits (20 days interval). Details of lesion counts and global assessment score were recorded at every follow up for primary and secondary outcome respectively. DLQI score was calculated at 4th follow up (end visit). Simultaneously, treatment emergent adverse events were recorded in suspected ADR reporting form for safety assessment.

\section{Statistical analysis}

Appropriate statistical software and Microsoft Excel 2007 were used for statistical analysis. For quantitative variables like age of onset of disease, mean and standard deviation were calculated. For other quantitative variables like lesion counts and DLQI score, median and range were calculated. For the evaluation of effectiveness and quality of life, ANOVA test, Krushkal-Wallis test, Wilcoxon test and Friedman test were used depending on normality of data by using Graph Pad Prism software free trial version 7.0. ${ }^{7}$ To know individual variation, post hoc test was used. Test of association, Chi square test or Fisher exact test was used for safety data evaluation.

\section{RESULTS}

A total 100 newly diagnosed patients of acne vulgaris were enrolled in this study. During study period, two patients did not come for follow up and one patient received oral acne therapy. So, data of these three patients were not included in the statistical analysis. The sociodemographic characteristics of the participants are represented in Table 1.

Common age of onset of acne was in 16-20 years group $(50.5 \%)$ followed by $11-15$ years group $(46.4 \%)$. Age of acne onset was $15.57 \pm 3.37$ years. Age of acne onset among male and female patients were $16.39 \pm 1.70$ years and $15.79 \pm 2.01$ years respectively. Majority of patients had grade II acne vulgaris followed by grade III acne vulgaris. Out of 97, majority of patients were treated with clindamycin (CLN) and benzoyl peroxide (BPO) combination therapy named as CLN and BPO group (Group A) followed by CLN and adapalene (ADA) combination named as CLN and ADA group (group B) and BPO and ADA combination named as BPO and ADA group (group C) which show in Table 2.

\section{Effectiveness assessment}

Primary effectiveness was measured by calculating the change of the total lesion count as well as inflammatory lesions and non-inflammatory lesions individually from baseline to 4th follow up. As shown in Table 3, within group analysis of the total lesion count at different time 
points showed a highly significant difference in all three groups (Friedman test; p value $<0.001$ ), but between the groups, there was no statistically significant difference in different visits (Krushkal-Wallis test; $p$ value $>0.05$ ). As shown in Table 4 and Table 5, within group analysis of the inflammatory lesion count and non- inflammatory lesion count at different time points showed a highly significant difference in all three groups (Friedman test; $p$ value $<0.001)$, but between the groups, there was no statistical significant difference in different visits (Krushkal-Wallis test; $\mathrm{p}$ value $>0.05$ ).

Percentage of patients at study end who demonstrated at least two scale improvements in the Investigator's Global Assessment (IGA) score were $51.2 \%$ (21 out of 41) in the group A, $46.7 \%$ (14 out of 30 ) in the group B and $42.3 \%$ (11 out of 26) in group C (Figure 1).

Table 1: Socio demographic characteristics $(n=97)$.

\begin{tabular}{|lll|}
\hline Variable & Total participants & Percentage (\%) \\
\hline Gender & & 45.5 \\
\hline Male & 44 & 54.6 \\
\hline Female & 53 & \\
\hline Age group (years) & & 63.9 \\
\hline $15-20$ & 62 & 28.9 \\
\hline $21-25$ & 28 & 4.1 \\
\hline $26-30$ & 04 & 3.1 \\
\hline $31-35$ & 03 & 00 \\
\hline Level of education & & 00 \\
\hline Primary (class 1-5) & 00 & 13.4 \\
\hline Upper primary (class 6-8) & 00 & 38.1 \\
\hline Secondary (class 9-10) & 13 & 48.5 \\
\hline Senior secondary (class 11-12) & 37 & \\
\hline Higher education (under graduate, post graduate) & 47 & 57.7 \\
\hline Occupation status & & 17.5 \\
\hline Student & 56 & 4.1 \\
\hline Job & 17 & 12.4 \\
\hline Business & 04 & 8.3 \\
\hline Housewife & 12 & \\
\hline Non-working & 08 & 4.1 \\
\hline Personal habits & & 01 \\
\hline Smoking & 04 & 2.1 \\
\hline Alcohol & 01 & 2.1 \\
\hline Tobacco & 02 & \\
\hline Smoking and alcohol & 02 & \\
\hline
\end{tabular}

Table 2: Clinical profile and therapeutic details of participants (n=97).

\begin{tabular}{|lll|}
\hline Variable & Total participants & Percentage (\%) \\
\hline Onset of acne (years) & & \\
\hline $11-15$ & 45 & 46.4 \\
\hline $16-20$ & 49 & 50.5 \\
\hline $21-25$ & 03 & 3.1 \\
\hline $26-30$ & 00 & 00 \\
\hline $31-35$ & 00 & 00 \\
\hline Grade of acne & & 79.4 \\
\hline Grade II & 77 & 20.6 \\
\hline Grade III & 20 & \\
\hline Therapy for acne & & 42.3 \\
\hline Group A (clindamycin and benzoyl peroxide) & 41 & 30.9 \\
\hline Group B (clindamycin and adapalene) & 30 & 26.8 \\
\hline Group C (benzoyl peroxide and adapalene) & 26 & \\
\hline
\end{tabular}


Table 3: Within and between group comparison of total lesion count.

\begin{tabular}{|lllll|}
\hline Visits & Total lesion count* & & \multicolumn{2}{c|}{ P value } \\
\hline Baseline & Group A $(\mathbf{n = 4 1})$ & Group B (n=30) & Group C (n=26) & 0.68 \\
\hline $\mathbf{1}^{\text {st }}$ follow-up & $27(19-29)$ & $27(23-30)$ & $27(22-30)$ & 0.09 \\
\hline $\mathbf{2}^{\text {nd }}$ follow-up & $22(12-26)$ & $23(16-29)$ & $22(18-26)$ & 0.73 \\
\hline $\mathbf{3}^{\text {rd }}$ follow-up & $18(8-27)$ & $19(14-25)$ & $17(14-24)$ & 0.15 \\
\hline $\mathbf{4}^{\text {th }}$ follow-up & $12(5-23)$ & $17(12-22)$ & $12(12-22)$ & 0.36 \\
\hline P value & $<0.001$ & $12(8-20)$ & $<0.001$ & \\
\hline
\end{tabular}

*Values are in median (range). Group A: CLN+BPO, Group B: CLN+ADA, Group C: BPO+ADA.

Table 4: Within and between group comparison of inflammatory lesion count.

\begin{tabular}{|lllll|}
\hline \multirow{2}{*}{ Visits } & Inflammatory lesion count* & & Group C (n=26) \\
\hline Baseline & Group A $(\mathbf{n = 4 1})$ & Group B (n=30) & $8(6-11)$ & 0.57 \\
\hline $\mathbf{1}^{\text {st }}$ follow-up & $8(5-11)$ & $8(6-11)$ & $6(3-8)$ & 0.18 \\
\hline $\mathbf{2}^{\text {nd }}$ follow-up & $6(2-8)$ & $6(2-8)$ & $3(1-7)$ & 0.98 \\
\hline 3 $^{\text {rd }}$ follow-up & $2(0-8)$ & $3(1-7)$ & $2(0-7)$ & 0.48 \\
\hline $\mathbf{4}^{\text {th }}$ follow-up & $2(0-6)$ & $2.5(1-7)$ & $1.5(0-8)$ & 0.81 \\
\hline P value & $<0.001$ & $2(0-6)$ & $<0.001$ & \\
\hline
\end{tabular}

*Values are in median (range). Group A: CLN+BPO, Group B: CLN+ADA, Group C: BPO+ADA.

Table 5: Within and between group comparison of non- inflammatory lesion count.

\begin{tabular}{|lllll|}
\hline \multirow{2}{*}{ Visits } & Non- inflammatory lesion count & G & \multicolumn{2}{c|}{ P value } \\
\hline Baseline & Group A $(\mathbf{n = 4 1})$ & Group B $(\mathbf{n = 3 0})$ & $19(15-22)$ & 0.68 \\
\hline $\mathbf{1}^{\text {st }}$ follow-up & $19(11-23)$ & $19(15-22)$ & $16(12-20)$ & 0.49 \\
\hline $\mathbf{2}^{\text {nd }}$ follow-up & $15(9-19)$ & $16(12-22)$ & $15(11-18)$ & 0.72 \\
\hline $\mathbf{3}^{\text {rd }}$ follow-up & $12(6-16)$ & $14.5(12-18)$ & $12(10-18)$ & 0.23 \\
\hline $4^{\text {th }}$ follow-up & $10(5-14)$ & $13(10-17)$ & $10(8-15)$ & 0.12 \\
\hline P value & $<0.001$ & $10(7-17)$ & $<0.001$ & \\
\hline
\end{tabular}

*Values are in median (range). Group A: CLN+BPO, Group B: CLN+ADA, Group C: BPO+ADA.

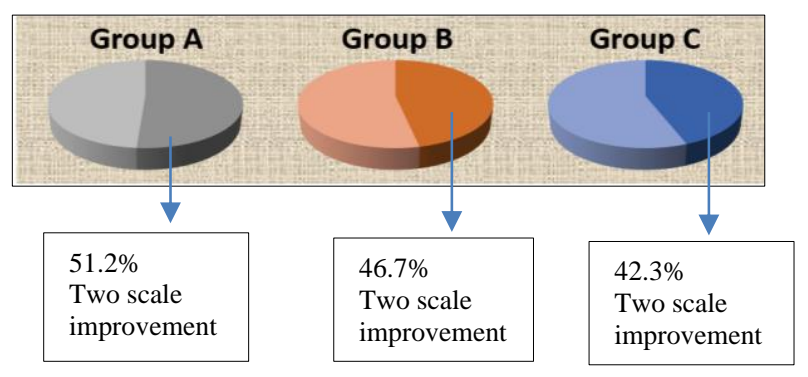

Table 6: Between group comparison of incidence of ADR.

\begin{tabular}{|c|c|c|c|c|}
\hline \multirow{2}{*}{$\begin{array}{l}\text { Incidence } \\
\text { of ADR }\end{array}$} & \multicolumn{4}{|c|}{ Number of participants } \\
\hline & Group A & Group B & Group C & Total \\
\hline Yes & 02 & 03 & 02 & 07 \\
\hline No & 39 & 27 & 24 & 90 \\
\hline Total & 41 & 30 & 26 & 97 \\
\hline
\end{tabular}

Figure 1: Improvement in IGA score.

Table 7: Within and between group comparison of DLQI score.

\begin{tabular}{|c|c|c|c|c|}
\hline \multirow{2}{*}{ Visits } & \multicolumn{3}{|l|}{ DLQI } & \multirow[t]{2}{*}{$P$ value } \\
\hline & Group A $(n=41)$ & Group B $(n=30)$ & Group C $(n=26)$ & \\
\hline Baseline & $11(7-19)$ & $11(5-17)$ & $10(4-17)$ & 0.61 \\
\hline $4^{\text {th }}$ follow-up & $3(0-6)$ & $4(0-7)$ & $4(0-7)$ & 0.06 \\
\hline P value & $<0.001$ & $<0.001$ & $<0.001$ & \\
\hline
\end{tabular}

*Values are in median (range). Group A: CLN+BPO, Group B: CLN+ADA, Group C: BPO+ADA. 


\section{Safety assessment}

As shown in Table 6, Out of 97, 07 patients developed adverse drug reactions. Observed adverse drug reactions were dryness of skin, pruritus and burning sensation over skin with level 1 severity. All ADRs were assessed as possible in its causality. All three treatments were well tolerated with minimal incidence of adverse drug reaction. There was no any statistically significant difference in the incidence of ADRs between Group A and B ( $\mathrm{p}=0.64)$; between group $\mathrm{A}$ and $\mathrm{C}(\mathrm{p}=1.00)$ and between group $\mathrm{B}$ and $\mathrm{C}(\mathrm{p}=0.63)$.

\section{Quality of life assessment}

As shown in Table 7, within group analysis of the DLQI score at different time points showed a highly significant difference in all three groups (Wilcoxon test; $p$ value $<0.001$ ), but between the groups, there was no statistically significant difference in different visits (Krushkal-Wallis test; $\mathrm{p}$ value $>0.05$ ).

\section{DISCUSSION}

According to the global burden of disease study, Acne vulgaris is an extremely common skin disease. A majority portion of the population experiences this condition in adulthood. ${ }^{8}$ Severity of the disease varies markedly from one individual to the other depending upon the interplay of various factors involved in the development of acne vulgaris. Grading systems based on the clinical appearance of lesions as well as lesion counting are useful in assessing the severity of acne vulgaris and outcome of therapy.

To target multiple pathophysiologic factors of acne vulgaris, topical agents with complementary mechanisms, such as antimicrobials and retinoids, are often combined. Topical retinoid-based combination therapy first recommended in 2003 by the global Alliance to improve therapeutic outcome and decrease development of resistance due to topical antibiotic monotherapy against $P$. acnes. ${ }^{9}$ In a therapeutic algorithm, topical combination therapy has become a standard first-line therapeutic approach in mild to moderate acne because this regimen attacks three major pathogenic factors of acne: abnormal keratinization and loss of desquamation in the infundibulum; $P$. acnes hypercolonization and primary inflammatory events.

As per Table 1, majority of the participants in our study were females $54.6 \%$. A study conducted by Gollnick et al and Langner et al showed $56.2 \%$ and $58.5 \%$ female participants in their studies. ${ }^{10,11}$ Acne vulgaris is seen more often in males than female. Yet, in our study, females outnumbered males. The predominance of females may be attributed to their higher level of awareness and concern about condition that presents as a cosmetic defect.
Majority of the participants in our study were in the age group of 15-20 years. A study conducted by Ghoshal et al and Dubey et al showed that most of the participants were in the range of 16-20 years and 16-23 years respectively. ${ }^{12,13}$ As shown in Table 2, onset of age of acne among female and male participants in present study were $15.57 \pm 2.01$ years and $16.39 \pm 1.70$ years respectively. Acne appeared nearly 10 months earlier in females than males related to their androgen activity. A study conducted by Al-Ameer et al showed that acne appeared nearly 18 months earlier in females which presumably related to their earlier onset of puberty. ${ }^{14}$

Despite the high prevalence of acne, there is too much wrong belief and deficiencies in the knowledge about disease. A study conducted by Poli et al showed that more than $80 \%$ of study participants did not believe acne to be a disease, but rather a normal phase of adolescence. ${ }^{15}$ Majority of participants in our study had higher educational status $(48.5 \%)$ and majority of participants were students $(57.7 \%)$ whom had enough knowledge and awareness about acne. A study conducted by Balakrishnan et al showed that $62.2 \%$ of participants had tertiary level of education. ${ }^{16}$ A study conducted by Darwish et al showed that $56.1 \%$ participants were students. ${ }^{17} \mathrm{We}$ know that patient's knowledge about disease is an essential part in its management. Health education program about acne is needed to improve which provide enough understanding about acne to common people.

Smoking was most common personal habit in participants in our study (6.2\%). Studies conducted by Adityan et al and Gollnick et al showed that 3.2\% and $18.1 \%$ participants were smokers respectively which noted that smoking is likely to bear a positive correlation with acne. ${ }^{18,19}$ Since the number of smokers was small, so no valid conclusion could be derived from our study. Impaired vasoreactivity, relative ascorbic acid deficiency, impaired collagen synthesis and wound healing in smokers may play some part in the underlying pathogenesis for the association between smoking and acne.

All new acne vulgaris cases were diagnosed clinically by dermatologist so any laboratory investigation was not advised. As per Table 2, more than two third of the participants had grade-II acne (79.4\%). A study conducted by Dubey et al and by Dudhia et al showed that $67.74 \%$ and $53 \%$ of participants had grade-II acne respectively. ${ }^{13,20}$ Majority of patients $(42.3 \%)$ were treated with clindamycin and benzoyl peroxide combination therapy named as CLN and BPO group (group A) followed by clindamycin and adapalene combination named as CLN and ADA group (group B) and benzoyl peroxide+ adapalene combination named as BPO and ADA group (group C).

To check effectiveness of topical combination therapy in our study we had used total lesion count; inflammatory 
lesion count and non-inflammatory lesion count. Similar methods were used to check effectiveness in a study conducted by Choudhury et al, Dubey et al and Kaur et al. ${ }^{13,21,22}$

As per Table 3-5, the percentage reduction of total lesion count was $63.1 \%$, inflammatory lesion count $76.5 \%$ and non-inflammatory lesion count $46.5 \%$ by the combination of topical $1 \%$ clindamycin and $2.5 \%$ benzoyl peroxide (group A). A study conducted by Shwetha et al showed percentage reduction in total lesion count was $51.0 \%$, for inflammatory lesion count $57.1 \%$ and for noninflammatory lesion count $49.0 \% .^{23}$ Another study conducted by Dubey et al showed percentage reduction in total lesion count was $83.9 \%$, for inflammatory lesion count $87.1 \%$ and for non-inflammatory lesion count $83.2 \% .^{13}$

The percentage reduction of total lesion count was $52.0 \%$, inflammatory lesion count $74.4 \%$ and non-inflammatory lesion count $42.3 \%$ by the combination of topical $1 \%$ clindamycin and $0.1 \%$ adapalene (Group B).The results of the previous studies with same topical combination in reducing total, inflammatory and non-inflammatory lesion counts were as follows: Wolf et al $46.7 \%, 55.0 \%$ and 42.5\%; Reddy et al- 46.5\%, 55.1\% and 42.8\%; and Prasad et al- $62.7 \%, 71.4 \%$ and $58.4 \%$ while the result of our study with the above combination was $52.0 \%, 74.4 \%$ and $42.3 \%$ respectively. ${ }^{24-26}$

Similarly, with the combination of topical $2.5 \%$ benzoyl peroxide and $0.1 \%$ adapalene (group $\mathrm{C}$ ) in the percentage reduction of total lesion count $52.8 \%$, inflammatory lesion count $75.6 \%$ and non-inflammatory lesion count $43.3 \%$ is similar to the study done by Gollnick et al wherein, the percentage reduction in total lesion count was $65.4 \%$, for inflammatory lesion count $70.3 \%$ and non-inflammatory lesion count $62.2 \% .^{10}$ Another study conducted by Thiboutot et al showed percentage reduction in total lesion count was $51.0 \%$, for inflammatory lesion count $62.9 \%$ and for non-inflammatory lesion count $51.2 \% .^{27}$

So, within and in-between group comparison of total lesion count, inflammatory lesion count and noninflammatory lesion count between all three treatment arms revealed almost similar effectiveness to reduce acne lesion counts. Similar results of within and in-between group comparison were seen in study conducted by Dubey et al and Choudhury et al. ${ }^{13,21}$

As shown in Figure 1, two scale improvement in IGA score is highest in clindamycin plus benzoyl peroxide combination (group A) which was 51.2\%. A study conducted by Choudhury et al showed $54.05 \%$ of two scale improvement in same treatment group. ${ }^{21}$

In the present study, about $92.7 \%$ participants did not show any adverse drug reaction during the treatment by all the three groups (Table 6). Only seven adverse drug reactions occurred during the study those were dryness of skin $(2.1 \%)$, pruritus $(4.1 \%)$ and burning sensation over skin $(1.0 \%)$ with level 1 severity. All ADRs were assessed as possible in its causality. A study conducted by Dubey et al showed $2.2 \%$ of dryness of skin and itching as ADRs in the participants who were prescribed clindamycin-benzoyl peroxide combination. Another study conducted by Dudhia et al showed only one ADR in their study. ${ }^{13,20}$

As per Table 7, percentage reduction of DLQI score, in clindamycin-benzoyl peroxide group (group A) from baseline to at the end of treatment in our study was $71.5 \%$ followed by clindamycin-adapalene group was $63.7 \%$ and benzoyl peroxide-adapalene group was $61.0 \%$. So, within and in-between group comparison of DLQI score between three treatment arms revealed almost similar improvement in quality of life by given topical therapy.

Limitation of our study were, it was uni-centric and openlabel study and had non-interventional design in which sample size was unequally distributed among all three groups. Reason of unequal distribution might be as it was an observational study not a randomized controlled trial. Limitation of our study could be overcome by a multicentric, double blind study with simultaneous microbial susceptibility testing. This could further reinforce the scientific evidence.

\section{CONCLUSION}

Majority of participants were females having age between 15-20 years who were students having higher level of education. Acne vulgaris appeared nearly 10 months earlier in females than males. All three topical combination drugs for mild acne vulgaris had similar effectiveness in terms of reduction in acne lesions with similar safety profile.

\section{ACKNOWLEDGEMENTS}

Authors would like to thank the faculty and staff of department of Dermatology for their support in this study.

Funding: No funding sources

Conflict of interest: None declared

Ethical approval: The study was approved by the Institutional Ethics Committee

\section{REFERENCES}

1. Tutakne MA, Vaishampayan SS. IAVDL Textbook of Dermatology. 3rd ed. Mumbai: Bhalani Publication House; 2008: 839-843.

2. Zaenglein AL, Graber EM, Thiboutot DM. Acne vulgaris and Acneiform eruptions. In: Goldsmith LA, Katz SI, Gilchrest BA, Paller AS, Leffell DJ, Wolff K, editor. Fitzpatrick's Dermatology in General Medicine. 7th ed. New York: McGraw Hill Companies; 2007: 687-703. 
3. Gollnick HP, Zouboulis CC. Not all acne is acne vulgaris. Dtsch Arztebl Int. 2014;111(17):301-12.

4. Gregoriou S, Kritsotaki E, Katoulis A, Rigopoulos D. Use of tazarotene foam for the treatment of acne vulgaris. Clin Cosmet Investig Dermatol. 2014;7:165-70.

5. Finlay AY, Khan GK. Dermatology Life Quality Index (DLQI) - A simple practical measure for routine clinical use. Clin Exp Dermatol. 1994;19(3):210-6.

6. Zaenglein AL, Pathy AL, Schlosser BJ, Alikhan A, Baldwin HE, Berson DS, et al. Guidelines of care for the management of acne vulgaris. J Am Acad Dermatol. 2016;74(5):945-73.

7. GraphPad Prism: Analyze, graph and present your scintific work. Available at: https://ww and w.graphpad.com/.

8. Seattle WI. GBD Compare. Seattle: University of Washington; 2013. Available at: http://www.healthdata.org/data-visualization/gbdcompare. Accessed on January 2019.

9. Gollnick HP, Cunliffe W, Berson D, et al. Management of acne: a report from a Global Alliance to Improve Outcomes in Acne. J Am Acad Dermatol. 2003;49(1):1-37.

10. Gollnick HP, Draelos Z, Glenn MJ, Rosoph LA, Kaszuba A, Cornelison R, et al. Adapalene-benzoyl peroxide, a unique fixed-dose combination topical gel for the treatment of acne vulgaris: a transatlantic, randomized, double-blind, controlled study in 1670 patients. Brit J Dermatol. 2009;161(5):1180-9.

11. Langner A, Chu A, Goulden V, Ambroziak M. A randomized, single-blind comparison of topical clindamycin+ benzoyl peroxide and adapalene in the treatment of mild to moderate facial acne vulgaris. Brit J Dermatol. 2008;158(1):122-9.

12. Ghoshal L, Banerjee S, Ghosh S, Gangopadhyay D, Jana S. Comparative evaluation of effectiveness of adapalene and azithromycin, alone or in combination, in acne vulgaris. Ind J Dermatol. 2007;52(4):179.

13. Dubey A, Amane H. Comparison of efficacy and safety of adapalene and benzoyl peroxideclindamycin combination in the topical treatment of acne vulgaris. IJBCP. 2016;5(5):1727-32.

14. Al-Ameer AM, Al-Akloby OM. Demographic features and seasonal variations in patients with acne vulgaris in Saudi Arabia: a hospital-based study. Inter J Dermatol. 2002;41(12):870-1.

15. Poli F, Auffret N, Beylot C, Chivot M, Faure M, Moyse D, et al. Acne as seen by adolescents: results of questionnaire study in 852 French individuals. Acta Dermato-Venereol. 2011;91(5):531-6.

16. Balakrishnan J, Appalasamy JR, Verma RA. study on awareness of skin infection among adults in petaling district, Malaysia. Int $\mathrm{J}$ Pharm Pharm Sci. 2015;8(2):136-9.

17. Darwish MA, Al-rubaya AA. Knowledge, Beliefs , and Psychosocial Effect of Acne Vulgaris among Saudi Acne Patients. ISRN Dermatol. 2013: 1-6.
18. Adityan B, Thappa DM. Pro P le of acne vulgaris- A hospital-based study from South India. Ind J Dermatol, Venereol Leprol. 2009;75(3):272.

19. Gollnick HPM, Friedrich M, Peschen M, Pettker R, Pier A, Streit V, et al. Safety and efficacy of adapalene $0.1 \%$ / benzoyl peroxide $2.5 \%$ in the longterm treatment of predominantly moderate acne with or without concomitant medication - results from the non-interventional cohort study ELANG. J Europ Acad Dermatol Venereol. 2015;29(4):15-22.

20. Dudhia S, Shah RB, Agrawal P, Shah A, Date S. Efficacy and safety of clindamycin gel plus either benzoyl peroxide gel or adapalene gel in the treatment of acne: a randomized open-label study. Drugs Ther Perspect. 2015: 3-7.

21. Choudhury S, Chatterjee S, Sarkar DK, Dutta RN. Efficacy and safety of topical nadifloxacin and benzoyl peroxide versus clindamycin and benzoyl peroxide in acne vulgaris: A randomized controlled trial. Ind J Pharmacol. 2011;43(6):628-31.

22. Kaur J, Sehgal VK, Gupta AK, Singh SP. A comparative study to evaluate the efficacy and safety of combination topical preparations in acne vulgaris. Int J Appl Basic Med Res. 2015;5(2):106-10.

23. Shwetha H, Geetha A, Revathi TN. Research Article A comparative study of efficacy and safety of combination of topical $1 \%$ peroxide in mild to moderate acne at a tertiary care hospital. J Chem Pharmaceut Res. 2014;6(2):736-41.

24. Wolf Jr JE, Kaplan D, Kraus SJ, Loven KH, Rist T, Swinyer LJ, et al. Efficacy and tolerability of combined topical treatment of acne vulgaris with adapalene and clindamycin: A multicenter, randomized, investigator-blinded study. J Am Acad Dermatol. 2003;49(3):211-7.

25. Reddy NB, Nandimath MK. Comparison of clinical efficacy of topical clindamycin with adapalene and adapalene alone in treatment of mild to moderate facial acne vulgaris. Int $\mathbf{J}$ Pharm Bio Sci. 2013;4:1079-88.

26. Prasad S, Mukhopadhyay A, Kubavat A, Kelkar A, Modi A, Swarnkar B, et al. Efficacy and safety of a nano-emulsion gel formulation of adapalene $0.1 \%$ and clindamycin $1 \%$ combination in acne vulgaris: A randomized, open label, active-controlled , multicentric, phase IV clinical trial. Indian J Dermatol Venereol Leprol. 2012;78(4):459-67.

27. Thiboutot DM, Weiss J, Bucko A, Eichenfield L, Jones T, Clark S, et al. Combination for the treatment of acne vulgaris: Results of a multicenter , randomized double-blind, controlled study. J Am Acad Dermatol. 2007;57(5):791-9.

Cite this article as: Patel RR, Karelia BN. A study of effectiveness and safety of topical combination therapy for acne vulgaris patients in dermatology department of a tertiary care teaching hospital. Int $\mathbf{J}$ Basic Clin Pharmacol 2020;9:458-64. 